\title{
A review of climate change in South East Asian Countries and human health: Impacts, vulnerability, adaptation, and mitigation
}

\author{
Anuji Upekshika Gamage ${ }^{1}$, Dess Pearson ${ }^{2}$, Fahad Hanna ${ }^{3}$ \\ ${ }^{1}$ Senior Registrar in Community Medicine, Ministry of Health Sri Lanka, Colombo, Sri Lanka. ${ }^{2}$ Visiting Lecturer, Course \\ Coordinator: Economics of Climate Change, University of Adelaide, Adelaide, Australia. ${ }^{3}$ Assistant Professor, Department of Public \\ Health, College of Health Sciences, Qatar University, Doha, Qatar.
}

\begin{abstract}
Climate Change (CC) is one of the most significant global environmental challenges humanity has faced. The most dominant causative factors due to human activity are emissions of greenhouse-gasses (GHG) from the combustion of fossil fuels and deforestation of natural rain forests. Although CC has a global impact, developing countries in the South East Asian Region (SEAR) would be more vulnerable to the effects as growth, development, poverty and health of these countries will be severely affected. The key ill-effects include increasing global average temperatures, the rise in sea levels, changes in eco-systems, and adverse impacts on human health. Rising sea levels threatens coastal cities; changes to the monsoon rainfall and a significant reduction in agricultural output are among some of the climate risks these countries will have to face. CC would compromise the essential prerequisites for good health; safe water, secure shelter, and food security and aggravate health risk through emerging and re-emerging diseases and spread of infectious diseases. Health-focused investments in climate actions remain weak and countries should focus on implementing health systems, while targeting for universal health coverage. The growth rate for Asian economies has risen over the past decade and this has led to steady emission increase. India and Indonesia are amongst the top ten emitters while others remain small emitters. Efforts are needed to limit the temperature increase to minimize adverse effects, which will require deep de-carbonization by both developed and developing countries, through an integrated portfolio of mitigation and adaptive strategies, which will be abide by UNFCCC common but differentiated approach.
\end{abstract}

Keywords: Climate change, health impacts, adaptation, mitigation, South East Asian countries.

\section{Introduction}

Climate change (CC) is the most significant global environmental challenge the human race has faced. It is defined as a long-term shift in weather conditions identified by changes in temperature, precipitation, winds, and other indicators. ${ }^{1}$ Factors that cause $\mathrm{CC}$ can be categorized as those related to natural processes and others related to human activity. ${ }^{2,3}$ The dominant causative factors due to human endeavour are the emission of greenhouse gasses (GHGs) from the combustion of fossil fuels and deforestation of natural rain forests. The primary product of fossil fuel combustion is carbon dioxide $\left(\mathrm{CO}_{2}\right)$, one of the harmful GHGs. ${ }^{2,3}$ Irrespective of the place of origin of the GHGs, they are absorbed into the atmospheric GHGs stock and subsequently spread around the globe. Since the world's Industrialized Revolution, the GHGs stock has continued to rise, and breakdown, which is contingent of the type of gas, may take from few decades to thousands of years. ${ }^{2}$ Thus, the GHGs absorb energy, slowing and preventing the loss of heat to space, making the earth warmer than it would otherwise be. This process is commonly known as the 'greenhouse effect' and has an enormous impact on global CC. ${ }^{4}$ Figure 1 shows the increase in GHG concentrations in the air over the last 2,000 years. Since the industrialized revolution, the levels of these gasses have risen markedly.

Figure 2 from global carbon project, ${ }^{6}$ depicts observed and future scenarios of global emissions for the period 1980 to 2100 . If 'business as usual' means an ongoing and unchanged state of affairs with limited mitigation,

\section{Practice Points}

- Climate change is a global threat, and the SEAR would be severely affected.

- Health impacts due to CC would be direct and indirect and would be aggravated by interacting with socioeconomic determinants of health.

- CC would create new poverty traps and exacerbate hunger, disease, and social disruption and the long run growth and development of these countries will be affected.

- The countries in SEAR should rethink their growth strategies to maximize future growth prospects and reduce their contribution to global warming through appropriate investment in adaptation and mitigation strategies.

- The health impacts can be controlled through adopting proactive measures such as public health preparedness.

carbon emissions would be around 30 Gigatons by 2100, which could result in a temperature increase of 3.2 to $5.4^{0} \mathrm{C}$.

Climate change will very likely cause environmental, social and economic damage in the future. ${ }^{8}$ The scale of the damages is difficult to estimate as projections models are still in their infancy and many countries do

Correspondence: Dr. Fahad Hanna, Assistant Professor, Department of Public Health, College of Health Sciences, Qatar University, Doha, Qatar. Email: fhanna@qu.edu.qa.

South East Asia Journal of Public Health 2016;6(2):3-10. (C) 2016 Gamage et al., publisher and licensee Public Health Foundation Bangladesh. This is an Open Access article which permits unrestricted non-commercial use, provided the original work is properly cited. 


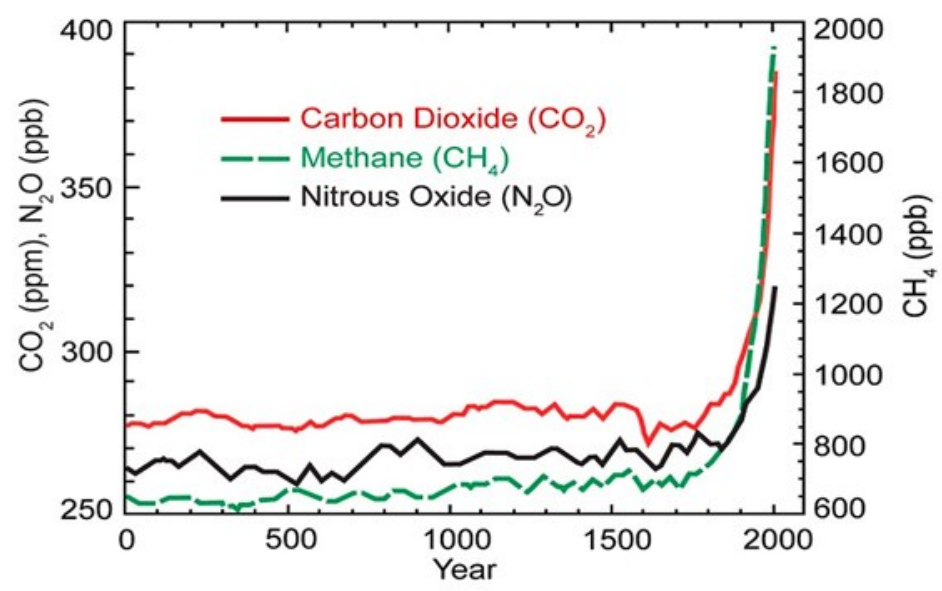

Figure 1: Green House Gas concentrations in the atmosphere over the last 2,000 years ${ }^{5}$

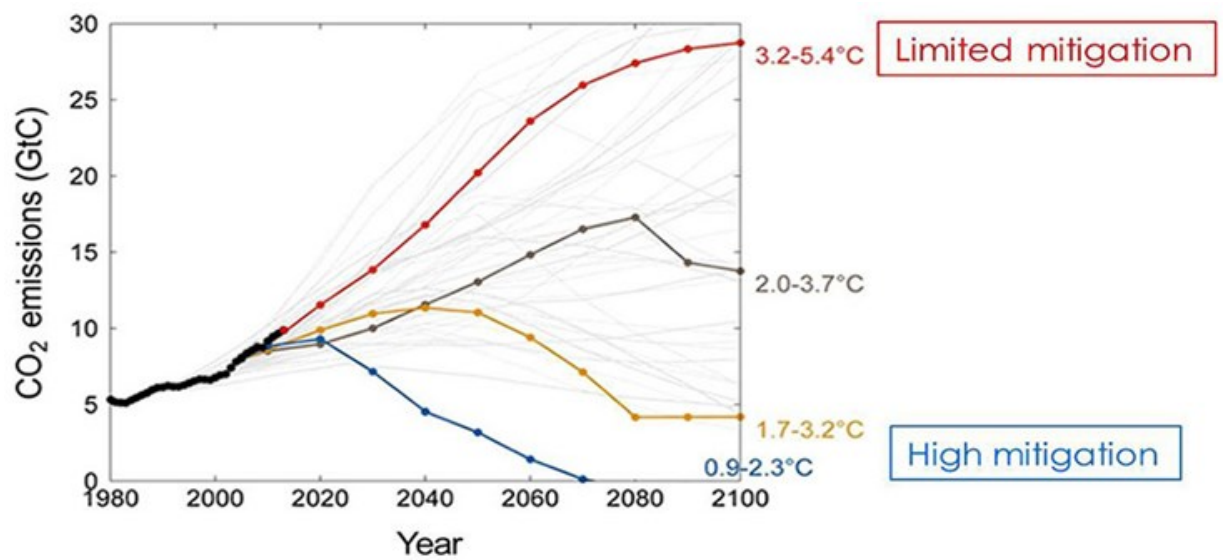

Figure 2: Observed and future scenarios of global emissions and resulting temperature rise ${ }^{6}$

not have the needed statistics for the projections. ${ }^{6}$ There is, also, considerable uncertainty about future land use and population distribution. Moreover, the present monetary value significantly relies on the 'discount rate' (DR) that is used. When deciding a DR for environmental issues, it is of importance that we consider the future generations' interest and take into account the consequences of such decision. Although $\mathrm{CC}$ is a global effect, the South and East Asia region would be significantly and invariably impacted (Table
1). Most damages in the region would arise from sea level rises, followed by extreme weather and disease. Based on these assumptions, the undiscounted net present value of unmitigated global damages due to $\mathrm{CC}$ is estimated at 500 trillion dollars. ${ }^{2,8}$

The developing countries must react now to implement adaptation and mitigation strategies to prevent future catastrophes. Developing countries may face challenges on the way to implementing clean technology while

Table 1: Net present value of climate change damages $2000-2100^{2}$

\begin{tabular}{|l|c|c|c|c|c|}
\hline Discount Rate & $\mathbf{0 \%}$ & $\mathbf{1 \%}$ & $\mathbf{3 \%}$ & $\mathbf{5 \%}$ & $\mathbf{1 0} \%$ \\
\hline Percentage by sector & \multicolumn{5}{|c|}{} \\
\hline Sea level rise & 57.8 & 61.1 & 68.6 & 75.1 & 82.1 \\
\hline Agriculture & 2.7 & 2.4 & 1.5 & 0.7 & -0.6 \\
\hline Extreme weather & 33.5 & 30.1 & 22.7 & 16.3 & 9.5 \\
\hline Health & 5.2 & 5.6 & 6.7 & 7.6 & 8.7 \\
\hline Percentage by sector & \multicolumn{5}{|c|}{0.3} \\
\hline *OECD-America & 0.3 & 0.3 & 0.3 & 0.3 & 0.3 \\
\hline OECD-Europe & 0.5 & 0.5 & 0.5 & 0.5 & 0.4 \\
\hline OECD-Pacific & 0.1 & 0.1 & 0.1 & 0.1 & 0.1 \\
\hline EE and FSU & -0.1 & -0.2 & -0.2 & -0.2 & -0.2 \\
\hline Middle East & 6.9 & 6.9 & 6.6 & 6.2 & 5.5 \\
\hline Central and South America & 12.3 & 12.7 & 13.6 & 14.5 & 15.8 \\
\hline Developing Asia & 48.4 & 48.1 & 47.9 & 48.5 & 50.6 \\
\hline Africa & 31.7 & 31.7 & 31.3 & 30.2 & 27.5 \\
\hline Total in Sbn. 1990 prices & $\mathbf{5 1 9 , 5 0 0}$ & $\mathbf{2 4 8 , 8 0 0}$ & $\mathbf{7 4 , 4 0 0}$ & $\mathbf{3 1 , 8 0 0}$ & $\mathbf{1 0 , 1 0 0}$ \\
\hline
\end{tabular}

*OECD - The Organization for Economic Co-operation and Development; **Eastern Europe and the Former Soviet Union.

South East Asia Journal of Public Health 2016;6(2):3-10 
achieving sustainable development. ${ }^{2,9,10}$ A successful program to combat $\mathrm{CC}$ must reconcile two goals; reduce GHG emissions and maintain the economic growth, which is referred to as carbon productivity or in other terms carbon efficiency. Some mitigation policies could generate revenues (e.g. carbon-taxes, ETS) and thereby provide better opportunities to stimulate growth through the revenues raised. ${ }^{2,9,10}$

The current review attempts to examine the impact of $\mathrm{CC}$ on South and East Asian Region (SEAR) and the current and projected health implications in this region. This paper identifies some adaptation and mitigation methods and thereby supports policymakers in decisionmaking.

\section{Materials and methods}

A comprehensive literature review on climate change and impact on health in the South East Asian Region was undertaken using the databases Medline, Embase, Biomed central, Science Direct, Web of Science, for relevant articles. Also useful websites, reports were looked up. The searches were conducted in December 2015. The search strategy for scientific literature consisted of free text and MeSH terms related to the following key words: 'Climate change, global warming, health impacts, adaptation, mitigation. The resulting hits were filtered for the occurrence of the term "South Asian countries". Systematic, reports and other reviews as well as research findings were considered. Literature published in the last 20 years, excluding those not in a peer reviewed journal, was included. The references of retrieved articles were manually searched for further material. The primary purpose of the search was to come to a collective decision on the type of action that needs to be taken to avoid catastrophic consequences due to climate change and global warming in the SEAR.

\section{Results and Discussion}

The key findings of the review in relation to $\mathrm{CC}$ are as follows:

\section{Impact on development}

The development of a country depends on three important factors; Labour, capital and environmental quality. ${ }^{11,12}$ The adverse effects of $\mathrm{CC}$ are expected to have negative impacts on all three factors. In addition, alleviation of poverty, malnutrition, and adverse health effects would be expected to increase child mortality, and affect an otherwise economically productive labor force. ${ }^{13,14}$ The inefficient workforce would subsequently affect future output and thereby growth and development of a country. Considering the baseline CC scenario, the loss of GDP in SEAR alone by 2100 is put at $3.5 \%{ }^{8}$ It is projected that CC driven GDP loss would drive more people below the poverty line. ${ }^{8,12}$

The developing countries argument is that reducing emissions may hinder the economic development of the respective countries and that the very poorest of countries should not sacrifice growth to combat CC. Developed countries emit around 4.3 tons of carbon per person. The countries of European Union emit 2.2 tons per person, while the developing countries emit 1.1 tons per person. ${ }^{2}$ The emissions per capita target in 2100 is 0.3 tons per person, which is less than onethird of what developing countries are emitting today; ${ }^{2}$ this emphasizes that all countries should make efforts in dealing with this global threat while at the same time achieving their economic development goals. In the short run, considering that developing countries are attempting to tackle $\mathrm{CC}$, growth could be hindered initially. ${ }^{8}$ Over the long term, the developing countries will be affected even more by $\mathrm{CC}$ in all sectors, and it will adversely affect growth and development of these countries (Table 1). Therefore, all countries will need to take measures immediately before the damages are irreversible, in which case the price would be too high, especially where human lives are involved. Developing countries need to explore climate resilient growth strategies keeping in mind policies that promote green technologies and technical transfers, which ultimately increase growth and development. Mitigation policies such as carbon taxes (CT) and Emission-TradingSystem (ETS) would generate revenues, and provide opportunities to stimulate growth through the income raised. ${ }^{8,15}$ The technological transfers and green funds that were discussed at Paris (UN Climate Change conference $30^{\text {th }}$ Nov- $12^{\text {th }}$ Dec, 2015) would enable the countries to enter into the development pathway through international mitigation efforts and maximize their future growth prospects. ${ }^{16}$

Health impact on SEAR countries

Based on World's Health Organization (WHO) classification, the South East Asian Region consists of 11 Member Countries. ${ }^{17}$ Namely, Bangladesh, Bhutan, Democratic People's Republic of Korea (DPRK), India, Indonesia, Maldives, Myanmar, Nepal, Sri Lanka, Thailand, and Timor-Leste. Table 2 shows gross domestic product (GDP), $\mathrm{CO}_{2}$ emissions

Table 2: GDP and $\mathrm{CO}_{2}$ emission by country in the $\mathrm{SEAR}^{18}$

\begin{tabular}{|l|c|c|c|}
\hline Country & GDP 2014 (US\$) & $\begin{array}{c}\text { CO2 emission in 2011 (metric } \\
\text { tons per capita) }\end{array}$ & $\begin{array}{c}\text { Health expenditure } \\
\text { (\%) of GDP) 2013 }\end{array}$ \\
\hline Bangladesh & 172.9 billion & 0.4 & 3.7 \\
\hline Bhutan & 1.959 billion & 0.8 & 3.6 \\
\hline India & 2.049 trillion & 1.7 & 4.0 \\
\hline Indonesia & 885.0 billion & 2.3 & 3.1 \\
\hline Maldives & 3.062 billion & 2.9 & 10.8 \\
\hline Myanmar & 64.33 billion & 0.2 & 1.8 \\
\hline Nepal & 19.77 billion & 0.2 & 3.0 \\
\hline Sri Lanka & 78.82 billion & 0.7 & 4.2 \\
\hline Thailand & 404.8 billion & 4.5 & 1.3 \\
\hline Timor-Leste & 1.417 billion & 0.2 & NA \\
\hline DPRK & 12.38 billion & 3.0 & \\
\hline
\end{tabular}

South East Asia Journal of Public Health 2016;6(2):3-10 
and health expenditures as a percentage of GDP by country in the SEAR.

Considering the temperature rises in this region, the Intergovernmental-Panel-on-Climate-Change (IPCC) projects the mean annual increase in temperature by the end of the century to be $3.3^{\circ} \mathrm{C}$ with the min-max range of 2.7 and $4.7^{\circ} \mathrm{C} .{ }^{19}$ The vulnerability and exposure of societies to climate-related hazards could vary in these regions because of differences in socio-demographic, economic, cultural, institutional and governance indicators. Most of these countries have experienced rapid and unplanned urbanization. The socio-economic inequality is vast in the region and poverty is a major factor in determining vulnerability to $\mathrm{CC}$, which will act as an aggravating and a predisposing factor for many emerging and re-emerging diseases. The countries in the SEAR rely heavily on agriculture for livelihoods, and this sector accounts for around $43 \%$ of total employment and contributes about $11 \%$ to $\mathrm{GDP}^{9}$ making the region highly susceptible to any extreme weather event associated with global warming. ${ }^{20}$

Today, the world is experiencing $\mathrm{CC}$ in tandem with other changes such as rapid urbanization, demographictransitions, land-use-change and depletion of freshwater resources, which are causative and magnifying factors of CC. ${ }^{16}$ Figure 3 depicts potential mechanisms by which $\mathrm{CC}$ could influence health. Climate factors would have direct, indirect ill-effects on health while at the same time interacting with socio-economic factors, prompting the emergence and re-emergence of infectious diseases..$^{20,21}$ Diseases linked to CC may vary from cardiovascular to respiratory diseases due to altered transmission of communicable diseases and malnutrition from crop failures. ${ }^{20}$ Due to projected changes in the hydro-cycle especially in SEAR, diarrhoeal disease-related morbidity and mortality would rise. ${ }^{22}$ Many serious infectious and mosquito-borne diseases such as dengue, malaria, and viral encephalitis are also predicted to be more prevalent as the temperature increases causing boost of potential breeding sites, which subsequently increases the spread of geographic range. Flooding due to extreme weather events will raise the incidence of water-borne infections caused by a variety of microorganisms, bio-toxins, and toxic contaminants. ${ }^{20,21,23}$ Moreover, the literature suggests that $\mathrm{CC}$ adversely affects mental health indirectly by inflicting stressors due to natural disasters on human settlements, adverse effects on livelihood and illness. ${ }^{24,25}$ The increase in acute and chronic mental health disorders would increase the burden on health systems. ${ }^{25,26}$ Some severe mental illnesses could ultimately result in suicide. ${ }^{27}$ Therefore, the developing countries of the SEAR would evidently face high disease burden, which needs to be accounted for while planning to combat $\mathrm{CC}$ challenges.

Climate change has become a certainty, thus the need for public health preparedness to anticipate, manage, and alleviate the health burdens it will impose, is vast. ${ }^{26}$ We must understand the differential effects of $\mathrm{CC}$ on various groups and the increased vulnerability of certain individuals, regardless of the socioeconomic status. Mothers and children, older people, certain occupational groups, may have higher vulnerability to CC and should be considered in public health preparedness plans. ${ }^{28}$

\section{DALY due to climate change}

WHO defines the burden of disease (BOD) as the total amount of disease or premature deaths within the population. ${ }^{30}$ The widely used measure of BOD, Disability-Adjusted-Life-Year (DALY), is the sum of years-of-life-lost (YLL) due to premature death and years of life lived with disability (YLD). ${ }^{30}$ The global burden attributable to $\mathrm{CC}$ was estimated by the WHO up to the year 2000, and model-based predictions were made of the health risks due to $\mathrm{CC}$ until 2030. ${ }^{31,32}$ In this assessment, the average climate from 1960 to 1991 was considered as the baseline. ${ }^{33}$ Epidemiological models were used to estimate elevated risk due $\mathrm{CC}$ on health outcomes such as malaria, diarrhoeal disease, malnutrition, flood deaths, direct effects of heat and cold. ${ }^{20,22}$

WHO reports that $\mathrm{CC}$ is responsible for $3 \%$ of the diarrhoeal, $3 \%$ of malaria and $3.8 \%$ of the dengue

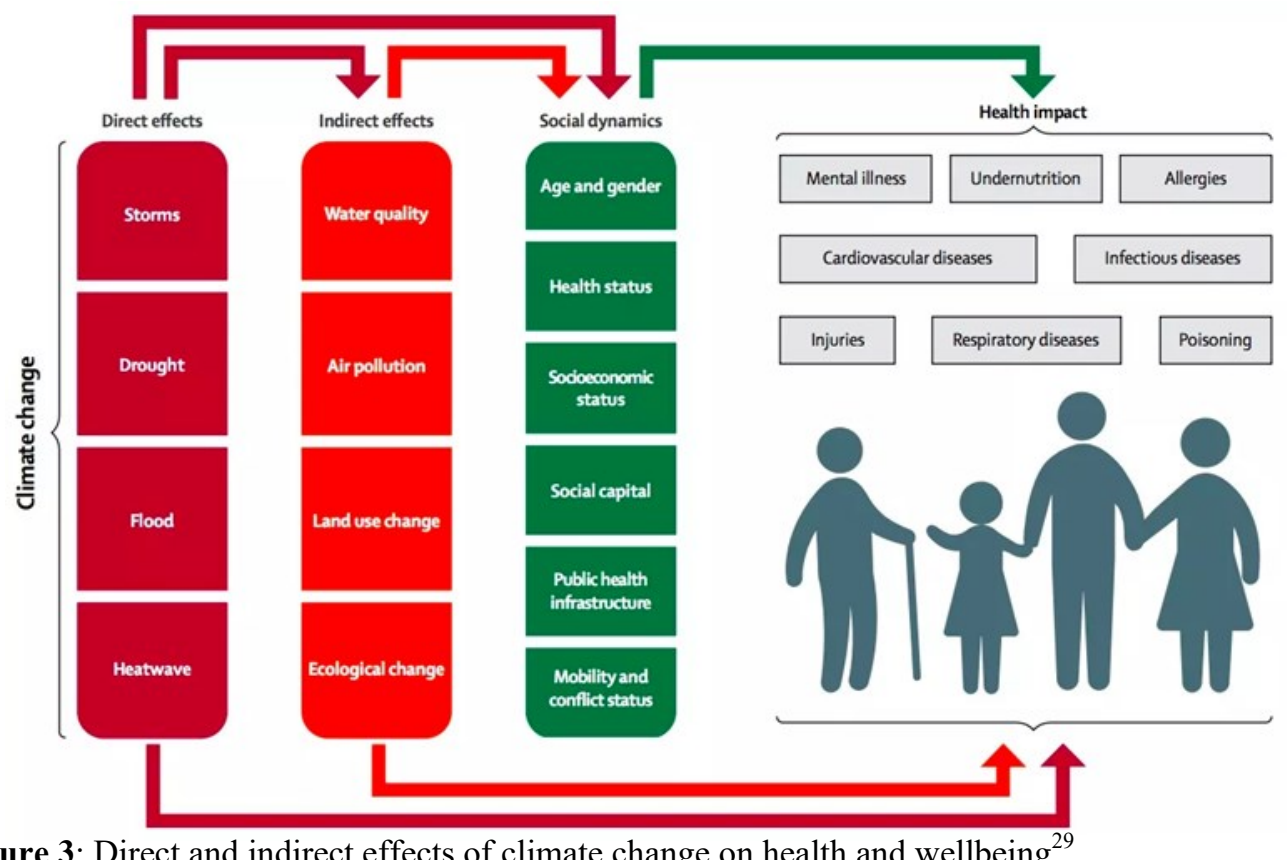

Figure 3: Direct and indirect effects of climate change on health and wellbeing ${ }^{29}$ 
fever-related deaths in the year 2004 worldwide. The attributable mortality due to $\mathrm{CC}$ accounted for $0.2 \%$ of the deaths worldwide. ${ }^{34}$ As shown in Table 3, developing countries will have to bear the highest burden of disease that would escalate due to impacts of $\mathrm{CC}^{33}$

Considering the projected health risks, it was estimated that excess risk due to CC would double by $2030 .^{34}$ The relative risk (RR) of diarrhoea would increase from 1.01 -1.02 in 2000 to $1.08-1.09$. The RR due to malnutrition would increase from 1.04 to 1.33 by 2030 compared to 2004 levels. Similar patterns of increase in RR are observed for flood-related diseases, cardiovascular diseases and malaria if unmitigated. ${ }^{32,35}$

\section{Mitigation and Adaptation}

Climate change and adverse health effects can be minimized or averted with evidence-based mitigation and adaptation strategies. ${ }^{2,8,37}$ Strategies for mitigation will protect the environment by reducing GHG emissions and adaptation is henceforth expected to reduce the adverse effects on the environment and human health, which cannot be avoided by mitigation alone. Mitigation mainly focuses on reducing $\mathrm{GHG}$ emission and enhancing carbon sinks by protecting existing carbon sinks like forests and oceans, or by creating new sinks to trap and remove carbon from the atmosphere. $^{38}$

Adaptation means the adverse effects of $\mathrm{CC}$ are anticipated, and appropriate action is taken to prevent or minimize the damages. ${ }^{39}$ Adaptation is a shared responsibility, and is multifaceted. Multi-sectoral collaboration is needed to contribute in adaptation methods against CC, which includes developing infrastructure, improving all aspects of public health and changes in production and consumption decisions to reduce the risk of $\mathrm{CC}$. $^{2}$ Mitigation and adaptation must go hand in hand for successful emission reduction efforts. ${ }^{2}$ It is also important to note that CC together with environmental impact should not be considered in isolation from the general economic, social and ecological systems and must be dealt through contextual multi-disciplinary approach suitable for the context to achieve sustainable development. The countries in the SEAR collectively contributed around $12 \%$ of the world's GHG emissions in the year $2000 .^{40}$ This is a significant increase (27\%) of the 1990 GHG emission. The land-use-change-and-forestry (LUCF) sector was the biggest source, ${ }^{41,42}$ contributing $75 \%$ of the region's total, while the energy industry and the agriculture sector contributed to $15 \%$ and $8 \%$, respectively. ${ }^{43}$ Hence, these areas could be targeted for adaptation and mitigation measures. Figure 4 shows potential health effects of $\mathrm{CC}$ and possible mitigation and adaptation measures that could be implemented.

\section{Mitigation}

As mitigation involves the process of reducing human-induced GHG-emissions through strategies that reduce GHG-emissions and enhance GHG-sinks, this section of the review will describe the potential mitigation techniques that could be implemented in the SEAR.

Land use is the type of activity being carried out on a unit of land, such as forestland, cropland, and grassland. Changes in the way land is used, i.e., clearing of forest for agriculture, reduce the carbon sinks. ${ }^{42,45}$ The primary mitigation strategies should, therefore, target these activities in the region. GHG emission reduction could be achieved by preserving rain forests while maximizing the use of available land for agriculture. Better land and farm management also include strategies to reduce non- $\mathrm{CO}_{2}$ emissions, such as reverse emissions from land use change and increase sequestration of carbon in the agro-ecosystem. Afforestation and reforestation, and improving forest management are additionally available strategies to sequester carbon by enhancing carbon sinks. ${ }^{45}$

One hundred and ninety-one countries ratified the Kyoto Protocol (KP), a milestone achievement in the international history of climate protection policy: consisting of the objectives of the UNFCCC in 1997. The KP introduced three flexible mitigation marketbased approaches for Annex one countries. ${ }^{2,46}$ These were the Joint Implementation (JI) mechanism, Clean Development Mechanism (CDM) and Emission trading system (ETS). The JI and CDM are two project-based mechanisms, whereas ETS is a non-project based and involves trading of emission permits within and between countries. From a developing country perspective, CDM and ETS are necessary.

A carbon tax (CT) is tax mechanism that can be employed for all emissions, which causes people to cut back on the use of carbon. ${ }^{2}$ Therefore, the price determines the level of emission. The ETS, on the other hand, works by setting a cap on emissions and requiring emitters to hold a permit for each ton of $\mathrm{CO}_{2}$ they emit. The level of the cap determines the number of permits available. Unlike the CT, in the ETS method, the cap determines the level of emissions. ${ }^{2}$ If emitters do not already hold a permit, they must either cut back on their emissions or buy a permit from another emitter who must then cut back. From the SEAR countries' point of view, both these tools would enable countries to cut down on carbon emission while at the same time generate revenues, which would subsequently provide opportunities to stimulate growth and encourage the use of renewable energy since this would not be subject to any carbon tax.

Table 5: Estimates of the impact of climate change in 2000 in thousands of DALYs ${ }^{36}$

\begin{tabular}{|l|c|c|c|c|c|c|}
\hline Regions & Malnutrition & Diarrhoea & Malaria & Floods & Total & $\begin{array}{c}\text { Total DALYs/ } \\
\text { million population }\end{array}$ \\
\hline African & 616 & 414 & 860 & 4 & 1894 & 3071.5 \\
\hline Eastern Mediterranean & 313 & 291 & 112 & 52 & 768 & 1586.5 \\
\hline Latin American/Caribbean & 0 & 17 & 3 & 72 & 92 & 188.5 \\
\hline South East Asian & 1918 & 640 & 0 & 14 & 2572 & 1703.5 \\
\hline Western Pacific & 0 & 89 & 43 & 37 & 169 & 111.4 \\
\hline Developed countries & 0 & 0 & 0 & 8 & 8 & 8.9 \\
\hline World & 2847 & 1460 & 1018 & 192 & 5517 & 920.3 \\
\hline
\end{tabular}

South East Asia Journal of Public Health 2016;6(2):3-10 


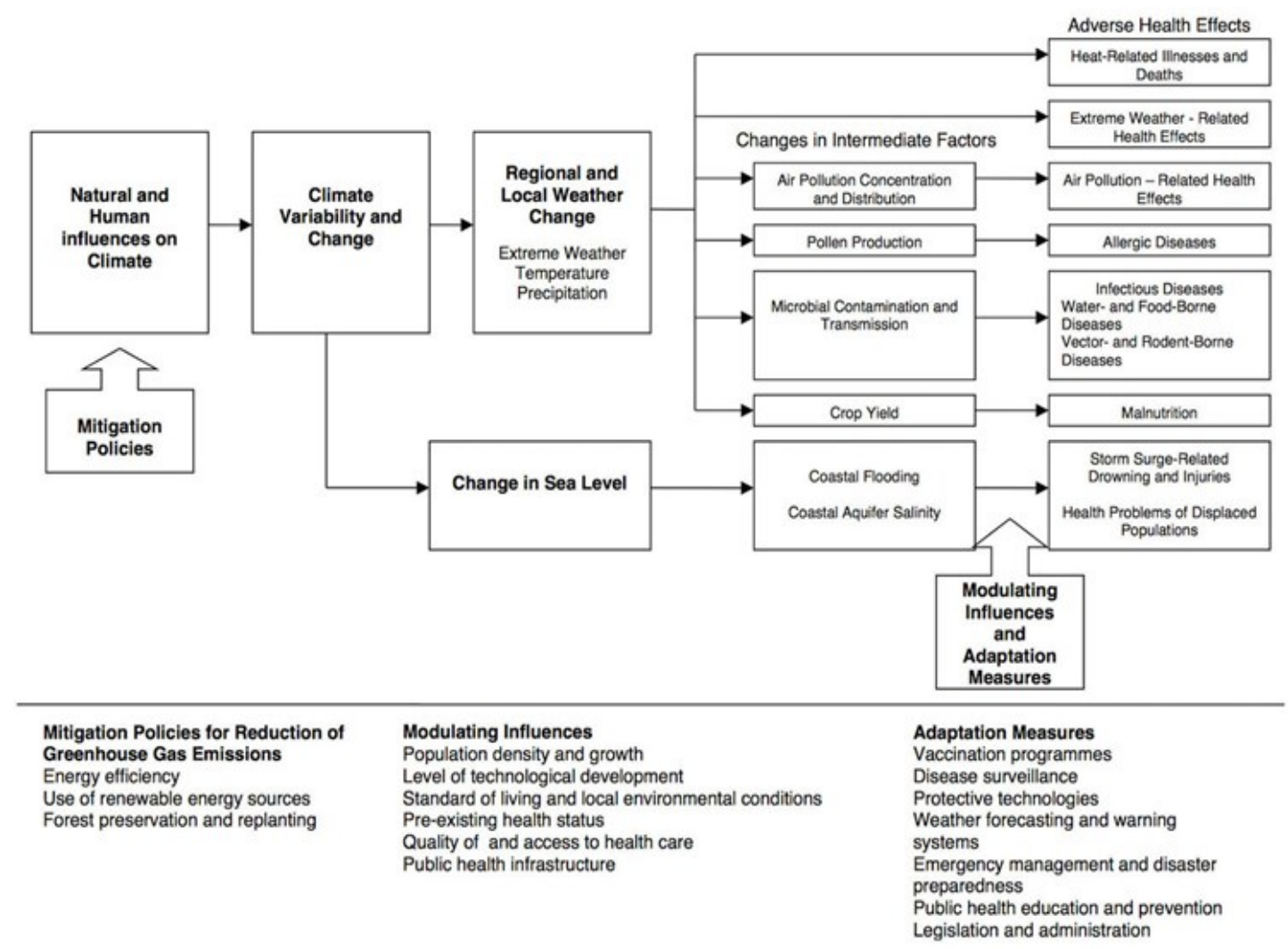

Figure 4: Potential health effects of climate change and possible mitigation and adaptation measures ${ }^{44}$

The CDM projects help developing countries through domestic emission-reducing projects that are entirely supported, technically and financially, by the Annex I countries. ${ }^{2}$ In addition to this, CDM provides incentives to developing countries to preserve the rainforests, which are carbon sinks, through mechanisms such as REDD (Reduced Emissions from Deforestation and Degradation). ${ }^{2}$ These projects can be used to generate emission reduction units, which can be later used by the countries to trade or to utilize as their reduction commitments. Developing countries are invited to make the most out of such opportunities.

\section{Adaptation}

The adaptation measures have to be multi-sectoral involving global and local partners and stakeholders. The developing countries need to develop adaptation strategies to suit the context to support the development of existing policies that exploit "no regret" measures and a "win- win" option. ${ }^{47}$ The basis for estimating adaptation costs is the economic opportunity cost of a product or activity. Energy, transport, agriculture and health-related adaptation methods are discussed below. Significant adaptation policy measures lead to increasing energy efficiency, a greater use of renewable energy and infrastructure development.

Notably, the SEAR's energy sector is a growing contributor to emissions, another untapped potential for mitigation. ${ }^{2,48-50}$ It is reported that in 2000, SEAR countries contributed approximately $3 \%$ of global energy-related $\mathrm{CO} 2$ emissions. ${ }^{2}$ The emissions are expected to rise significantly with rapid development and population growth compared to the rest of the world, in business as usual scenario. Switching to renewable energy sources and use of cleaner black coal instead of brown coal are strategies that would reduce $\mathrm{CO}_{2}$ emissions. ${ }^{2}$ Additionally, efficient use of energy should be targeted. The literature suggests that by improvement and conservation in buildings and industry sectors such as the use of efficient lighting and electrical appliances, energy saving and better insulation, energy can be preserved. Electricity subsidies are heavily utilized in the countries of the region, and this has an adverse impact on emissions leading to unnecessary overuse and wastage of electricity. ${ }^{2}$ Also, funding these subsidies could otherwise be invested in the economically productive activity or re-directed in the form of income support measures to the very poor in order to alleviate poverty.

According to the Asian Development Bank, ${ }^{9}$ transport alone was responsible for $23 \%$ of global GHG emissions and it is expected to escalate to $31 \%$ worldwide by 2030. Policies that would enhance the use of cleaner fuels/hybrid or electric transport and infrastructure development to promote railway and public transport should also be implemented.

The adaptation strategies for agriculture sector suitable for SEAR are adjusting cropping calendar and crop rotation; to develop and encourage the use of highyielding varieties and sustainable technological applications. ${ }^{2,}$ Moreover, reduction of GHG emissions by taxing nitrogen fertilizers and reforming agricultural support policies to limit the use of nitrogen fertilizers would be a helpful measure. Considering the health sector, as noted earlier, most activities suggested are preventive measures. ${ }^{26}$ These include improving surveillance, monitoring, and dissemination of disease as well as outbreak investigation. Improvements in the healthcare system are warranted and staff must be well 
equipped and geared with appropriate skills and technology to treat the emerging and re-emerging diseases. It is also of importance to educate the public to be vigilant and to raise awareness of infectious and vector-borne diseases. ${ }^{20,21,23,25,29,34,37,44}$ Countries must invest in infrastructure for proper waste disposal and improve sanitation facilities as it may mitigate the spread of most infectious diseases as well as reduce air and water pollution. Implementing and monitoring vaccine programs for vaccine-preventable diseases is another key suggestion. ${ }^{51,52}$ It should be emphasized that much damage could be instigated by extreme weather events such as floods and heat waves. Therefore, countries must be equipped with flood and drought management and associated disaster preparedness system. Continuous monitoring and analysis of the main climatic elements are undoubtedly necessary while it is also important to improve weather forecasting systems, as this would assist in preparedness. ${ }^{53}$

\section{Conclusion}

Climate change is a global threat, and the SEAR would be severely affected. Health impacts due to CC would be direct and indirect and would be aggravated by interacting with socioeconomic determinants of health. CC would create new poverty traps and exacerbate hunger, disease, and social disruption and the long run growth and development of these countries will be affected. Therefore, developing countries need to plan new growth and development strategies while at the same time reduce their contribution to global warming through appropriate investment in adaptation and mitigation strategies. Understanding the threats that CC poses on health is also vital for public health preparedness, ${ }^{26}$ and would help in strategizing plans to tackle the ongoing and emergent threats. Public health issues in relation to environmental and social issues should be prioritized, integrating climate and meteorological observations to real-time public health issues such as emerging and re-emerging diseases and long- term climate models to estimate human exposure risks and burden of disease.

\section{Competing interest}

The authors declare that they have no competing interests.

\section{References}

1. $\mathrm{Wu} \mathrm{X,} \mathrm{Lu} \mathrm{Y,} \mathrm{Zhou} \mathrm{S,} \mathrm{Chen} \mathrm{L,} \mathrm{Xu} \mathrm{B.} \mathrm{Impact} \mathrm{of}$ climate change on human infectious diseases: Empirical evidence and human adaptation. Environ Int 2016;86:14-23.

2. Owen $\mathrm{AD}$, Henley $\mathrm{N}$ (editors). The Economics of Climate Change. New York: Routledge, 2004.

3. Asian Development Bank. Bio-Brief\#2: Climate Change. uploads/2014/12/biobrief21 TA7833 climate change LAO 2013.pd $\underline{\text { f }(\text { accessed Dec 2016) }}$

4. Houghton JT, Jenkins GJ, Ephraums J. Climate change: the IPCC scientific assessment. World Metrological Organization and United Nations Environment Programme. Cambridge: Cambridge University Press, 1990.

5. United States Environmental Protection
Authority. Causes of Climate Change. http:// www3.epa.gov/climatechange/science/ causes.html (accessed Dec 2016)

6. Stocker TF, Qin D, Plattner GK, Tignor M, Allen SK, Boschung J, Et al. (eds.). Summary for Policymakers. In: Climate Change 2013: The Physical Science Basis. Contribution of Working Group I to the Fifth Assessment Report of the Intergovernmental Panel on Climate Change (IPCC). Cambridge: Cambridge University Press, 2013.

7. Environment and Climate Change Canada. Projecting Future Climate Change. http:// www.ec.gc.ca/sc-cs/Default.asp? lang=En\&n=A5F83C26-1 - _ s05 (accessed Dec 2016)

8. Stern N. The Economics of Climate Change: The Stern Review. Cambridge: Cambridge University Press, 2007.

9. Asian Development Bank. The Economics of Climate Change in Southeast Asia: A Regional Review. Manila: Asian Development Bank, 2009.

10. Ellis K. Must developing countries sacrifice growth to save the planet? London: Overseas Development Institute (ODI), 2009.

11. Cole MA. Trade, the pollution haven hypothesis and the environmental Kuznets curve: examining the linkages. Ecol Econ 2004;48(1):7181.

12. Stern DI. The rise and fall of the environmental Kuznets curve. World Dev 2004;32(8):1419-39.

13. Bosello F, Roson R, Tol RS. Economy-wide estimates of the implications of climate change: Human health. Ecol Econ 2006;58(3):579-91.

14. Fankhauser S, Tol RS. On climate change and economic growth. Resour Energy Econ 2005;27 (1):1-17.

15. Sathaye J, Shukla P, Ravindranath N. Climate change, sustainable development and India: Global and national concerns. Curr Sci Bangalore 2006;90(3):314.

16. UNFCCC. Historic Paris Agreement on Climate Change :195 Nations Set Path to Keep Temperature Rise Well Below 2 Degrees Celsius. $\quad$ http://newsroom.unfccc.int/unfcccnewsroom/finale-cop21/ (accessed Dec 2016)

17. World Health Organization. WHO South-East Asia Countries. http://www.searo.who.int/ about/en/ (accessed Dec 2016)

18. World Bank. World Development Indicators. http://data.worldbank.org/indicator/ NY.GDP.MKTP.KD.ZG/countries/ (accessed Dec 2016)

19. Christensen JH, Hewitson B, Busuioc A, Chen A, Gao X, Held I, et al. Regional Climate Projections. Climate Change 2007: The Physical Science Basis. https://www.ipcc.ch/ publications and data/

publica-

tions ipcc fourth assessment report wg1 repo rt the physical science basis.htm (accessed Dec 2016) 
20. McMichael AJ. Impact of climatic and other environmental changes on food production and population health in the coming decades. Proc Nutr Soc 2001;60:195-201.

21. Patz JA, Epstein PR, Burke TA, Balbus JM. Global climate change and emerging infectious diseases. JA MA 1996;275(3):217-23.

22. Solomon S, Qin D, Manning M, Chen Z, Marquis M, Averyt KB, et al. The Physical Science Basis. Contribution of Working Group I to the Fourth Assessment Report of the Intergovernmental Panel on Climate Change (IPCC). Cambridge: Cambridge University Press, 2007.

23. Patz JA, Campbell-Lendrum D, Holloway T, Foley JA. Impact of regional climate change on human health. Nature 2005;438(7066):310-7.

24. Chand PK, Murthy P. Climate change and mental health. Regional Health Forum 2008;12 (1):43-8.

25. Berry HL, Bowen K, Kjellstrom T. Climate change and mental health: a causal pathways framework. Int J Public Health 2010;55(2):12332.

26. Frumkin H, Hess J, Luber G, Malilay J, McGeehin M. Climate Change: The Public Health Response. Am J Public Health 2008;98 (3):435-45.

27. Kessler RC, Galea S, Gruber MJ, Sampson NA, Ursano RJ, Wessely S. Trends in mental illness and suicidality after Hurricane Katrina. Mol Psychiatry 2008;13(4):374-84.

28. Younger M, Morrow-Almeida HR, Vindigni SM, Dannenberg AL. The built environment, climate change, and health: opportunities for co-benefits. Am J Prev Med 2008;35(5):517-26.

29. Watts N, Adger WN, Agnolucci P, Blackstock J, Byass P, Cai W, et al. Health and climate change: policy responses to protect public health. Lancet 2015;386(10006):1861- 914.

30. Mathers C, Fat DM, Boerma JT. The global burden of disease: 2004 update. Geneva: World Health Organization, 2008.

31. Simon H, Sari K, Simon L, Diarmid C-L. Quantitative risk assessment of the effects of climate change on selected causes of death, 2030s and 2050s. Geneva, Switzerland, 2014.

32. Anthony JM, Diarmid C-L, Sari K, Sally E, Paul $\mathrm{W}$, Wilson $\mathrm{T}$, et al. Global climate change. Comparative Quantification of Health Risks: Global and Regional Burden of Disease due to Selected Major Risk Factors: Geneva, Switzerland, 2004.

33. World Health Organization. Global Health Risks: Mortality and Burden of Disease attributable to selected major risks. Geneva Switzerland WHO, 2009.

34. World Health Organization. The World Health Report 2002. Geneva, Switzerland; 2002.

35. McMichael AJ. Globalization, climate change, and human health. NEMJ 2013;368(14):133543.
36. European Union. European Commission. Guidance on Integrating Climate Change and Biodiversity into Strategic Environmental Assessment. Brussels: European Union, 2013.

37. Levina E, Tirpak D. Adaptation to climate change. Key Terms. Paris: Organisation For Economic Co-Operation and Development (OECD), 2006.

38. McMichael AJ. The urban environment and health in a world of increasing globalization: issues for developing countries. Bull World Health Organ 2000;78(9):1117-26.

39. Fearnside PM. Global warming and tropical land-use change: greenhouse gas emissions from biomass burning, decomposition and soils in forest conversion, shifting cultivation and secondary vegetation. Clim change 2000;46(12):115-58

40. Kalnay E, Cai M. Impact of urbanization and land-use change on climate. Nature 2003;423 (6939):528-31.

41. Zhuang J, Suphachalasai S, Samson JN. The Economics of Climate Change in Southeast Asia. Asia Security Initiative Policy Series: Working Paper No. 9 (ed.). Singapore: RSIS Center for Non-traditional Security Studies, 2010.

42. Haines A, Patz JA. Health effects of climate change. JA MA 2004;291(1):99-103.

43. Pan Y, Birdsey RA, Fang J, Houghton R, Kauppi PE, Kurz WA, et al. A large and persistent carbon sink in the world's forests. Science 2011;333(6045):988-93.

44. United Nations Framework Convention on Climate Change. Kyoto Protocol. http:// unfccc.int/kyoto protocol/items/2830.php (accessed Dec 2016)

45. Centre for European Policy Studies. Global Sectoral Industry Approaches to Climate Change: The Way Forward. CEPS Task Force Report. Brussels: Centre for European Policy Studies, 2008.

46. Ellis J, Treanton K. Recent trends in energy-related CO 2 emissions. Energy Pol 1998;26(3):159-66.

47. Global Carbon Project. IPCC AR5 Carbon. http://www.globalcarbonproject.org/news/IPCCAR5-Carbon.html (accessed Dec 2016)

48. Thompson RL, Patra PK, Chevallier F, Maksyutov S, Law RM, Ziehn T, et al. Topdown assessment of the Asian carbon budget since the mid 1990s. Nat Commun 2016;7.

49. Haines A, Kovats RS, Campbell-Lendrum D, Corvalán C. Climate change and human health: impacts, vulnerability and public health. Public Health 2006;120(7):585-96.

50. Smit B, Burton I, Klein RJT, Wandel J. An Anatomy of Adaptation to Climate Change and Variability. Clim Change 2014;45(1):223-51.

51. Costello A, Abbas M, Allen A, Ball S, Bell S, Bellamy R, et al. Managing the health effects of climate change. Lancet 2009;373(9676):1693733. 